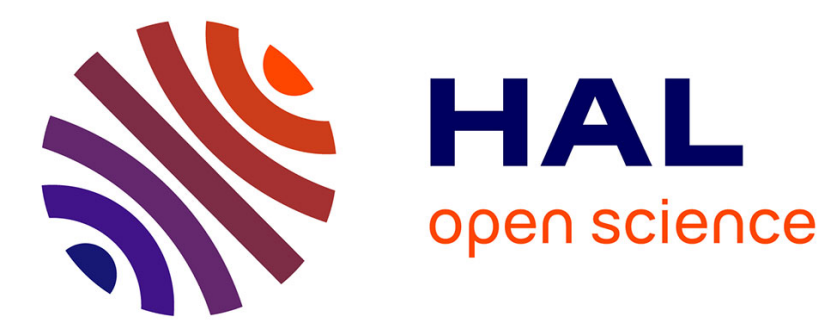

\title{
Asymptomatic Internal Carotid Aneurysm: An Uncommon Disease of the Carotid Arteries
}

Lucien Chassin-Trubert, Baris Ata Ozdemir, Youcef Lounes, William Alonso, Ludovic Canaud, Pierre Alric

\section{- To cite this version:}

Lucien Chassin-Trubert, Baris Ata Ozdemir, Youcef Lounes, William Alonso, Ludovic Canaud, et al.. Asymptomatic Internal Carotid Aneurysm: An Uncommon Disease of the Carotid Arteries. Annals of Vascular Surgery, 2021, 70, pp.570.e1-570.e5. 10.1016/j.avsg.2020.08.127 . hal-03130061

\section{HAL Id: hal-03130061 \\ https://hal.science/hal-03130061}

Submitted on 18 Aug 2021

HAL is a multi-disciplinary open access archive for the deposit and dissemination of scientific research documents, whether they are published or not. The documents may come from teaching and research institutions in France or abroad, or from public or private research centers.
L'archive ouverte pluridisciplinaire HAL, est destinée au dépôt et à la diffusion de documents scientifiques de niveau recherche, publiés ou non, émanant des établissements d'enseignement et de recherche français ou étrangers, des laboratoires publics ou privés. 


\title{
Asymptomatic Internal Carotid Aneurysm: An Uncommon Disease of the Carotid Arteries
}

\author{
Lucien Chassin-Trubert, ${ }^{1,2}$ Baris Ata Ozdemir,, Youcef Lounes, ${ }^{1}$ William Alonso, \\ Ludovic Canaud, ${ }^{1}$ and Pierre Alric, ${ }^{l}$ Montpellier, France; Bristol, UK
}

\begin{abstract}
Despite a low-incidence extracranial carotid artery aneurysm (ECAA) disease has important clinical repercussion that obliges understanding and knowledge of correct treatment. The 2 dominant etiologies are atherosclerotic degeneration and pseudoaneurysm. The natural history of ECAAs is understood. Neck pain, a pulsatile mass and central or peripheral neurological manifestations are the most common symptoms. Recommendations for diagnosis and treatment are not uniform and still under discussion, representing a challenge for clinicians. We discuss a case of $2.5 \mathrm{~cm}$ asymptomatic saccular atherosclerotic ECAA treated surgically in light of the most recent literature.
\end{abstract}

\section{INTRODUCTION}

Extracranial carotid artery aneurysm (ECAA) is an uncommon pathology, reported in the literature as individual clinical cases or small series. In $67 \%$, the aneurysm involved the internal carotid artery (ICA), 32\% the common carotid artery (CCA) bifurcation, and $1 \%$ the external carotid artery (ECA) in the multicentric Serbian study. ${ }^{1}$ The definition of ECAA is unclear. Although the classic definition for an arterial aneurysm is the permanent localized dilation of the diameter of an artery of at least $50 \%$ as compared with the expected norm of the artery in question, ${ }^{2}$ it has been suggested to define ECAA as the permanent dilatation of the bulbus greater

Conflict of interest: None.

Source of funding: No funding was provided.

${ }^{1}$ Department of Thoracic and Vascular Surgery, Arnaud de Villeneuve Hospital, Montpellier, France.

${ }^{2}$ Clinica Universidad de los Andes, Servicio de Cirugía Vascular y Endovascular, Chile.

${ }^{3}$ University of Bristol, Bristol, UK.

Correspondence to: Lucien Chassin-Trubert, Service de Chirurgie Vasculaire et Thoracique, Hôpital Arnaud de Villeneuve, 191 av Doyen Gaston Giraud, 34090 Montpellier, France; E-mail: info@cirujanovascular.cl than $200 \%$ of the diameter of the normal ICA or greater than $150 \%$ of the diameter of the normal CCA. $^{2}$ ECAA etiology is diverse and ranges from atherosclerosis, infection, fibromuscular dysplasia, and connective tissue disease, to traumatic or spontaneous dissection. ECAAs are present with a slightly greater frequency in men and are exceptionally bilateral. ${ }^{3}$ Historically, ECAAs were diagnosed clinically with symptoms and signs secondary to cerebrovascular events, cervical masses, or pain, but in the era of modern imaging, many asymptomatic ECAAs are discovered incidentally. ${ }^{3}$ Although rare, ECAAs have important clinical repercussions that necessitate understanding and knowledge of appropriate management. Treatment options include medical management, open surgery, and endovascular intervention and should be individualized to the patient for best outcome. There is no clear guideline, expert consensus, or treatment algorithm for the treatment of this disease.

\section{CASE REPORT}

We report on a 58-year-old female patient who was referred to our vascular surgery service for a right pulsatile neck mass of a few days. Carotid duplex scanning revealed a $25-\mathrm{mm}$ diameter right extracranial internal carotid artery aneurysm. There was no history of cerebrovascular symptoms, neck pain, or cervical trauma, but the patients past medical history included hypertension and a congenital ostium secundum atrial septal defect. The nontender 


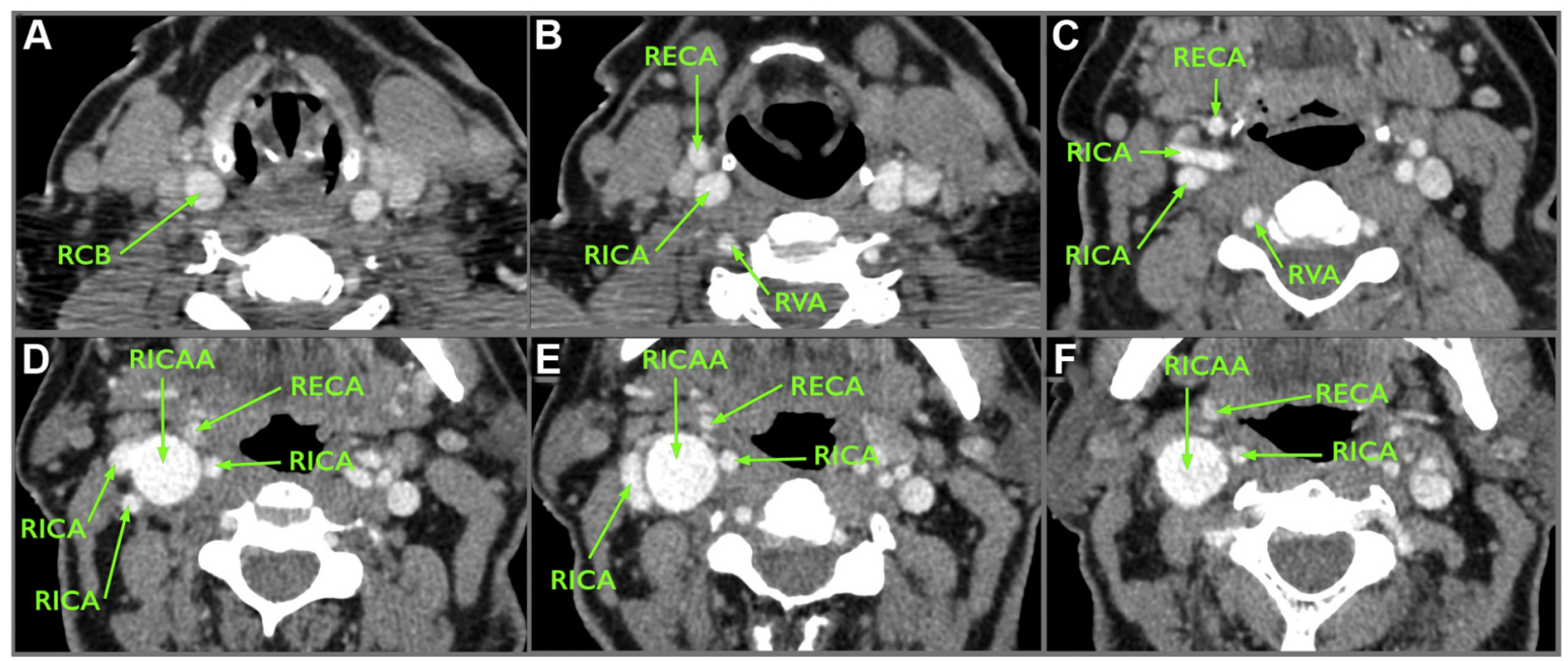

Fig. 1. Series of axial computed tomography angiography images from caudal to cranial. (A) The right carotid bifurcation $(\mathrm{RCB})$. (B) The right internal carotid artery (RICA) and right external carotid artery (RECA) after the RCB. The right vertebral artery (RVA) at the bottom of the image. (C-F) 25-mm diameter right internal carotid artery aneurysm (RICAA) without thrombus; note the redundancy and tortuous tract of the RICA. mass was located anterior to the right sternocleidomastoid muscle in zone 2 of the neck ${ }^{4}$ and there was a bruit on auscultation. No other anomalies were identified on physical examination. High-resolution CTA confirmed a 25$\mathrm{mm}$ diameter saccular aneurysm localized in the proximal segment of a redundant looped right internal carotid artery without intraluminal thrombus (Figs. 1 and 2A). No other aneurysms were identified in the cerebral circulation. Blood chemistry and hematology values were all in the normal range. The patient was scheduled for surgical repair by resection of the aneurysm with restoration of anatomic continuity. The right carotid bifurcation with his branches and the aneurysm were exposed through a standard anterior cervical incision (Fig. 2B). The ICA was redundant and tortuous in the zone of the aneurysm. Retraction of the aneurysm down to the incision zone was required to obtain proximal and distal control of the aneurysm (Fig. 2C). About 5,000 intravenous units of heparin where administered before proximal and distal clamping. After aneurysm resection, a Sundt shunt (Integra NeuroSciences) was inserted between the common and internal carotid arteries (Fig. 2D). Direct end-to-end repair with 50 prolene was possible between the ICA and the common carotid artery due to redundancy of the ICA (Fig. 2E). The patient recovered uneventfully without neurological symptoms. She was discharged on the fourth postoperative day with daily antiplatelet treatment. The bacteriological examination of the aneurysm was negative. Histology revealed atheroma without ulceration or thrombosis, thinned media, and rarefaction of the elastic component which was replaced by fibrous tissue. With 12 months postoperative follow-up, the patient remains asymptomatic and the surgical revascularization remains patent.

\section{DISCUSSION}

In line with aneurysms elsewhere in the body, ECAAs can be true or false. The principal etiological causes of true ECAA include atherosclerosis, arteritis, fibromuscular dysplasia, Marfan's syndrome, and medial degeneration. The commonest causes of false ECAAs include iatrogenic, post carotid endarterectomy, infection, post-trauma, and postdissection. Unlike most larger and recent series ${ }^{5-8}$ where false ECCAs are the most frequent etiology composing between $12.5 \%$ and $82 \%$ of cases, our patient presented with a true atherosclerotic ECAA. This is the etiology reported in $35 \%$ to $66 \%$ of series. In our opinion, the differentiation between a true and false aneurysm is of clinical importance as true aneurysms are often responsible for cerebral embolism causing neurological impairment because of the presence of significant amount of intraluminal thrombus relative to false aneurysms. ${ }^{8}$ Furthermore, we recommend the use of autologous instead of prosthetic reconstruction in patients with false aneurysms because of the associated with infection.

Although ultrasound represents the present-day modality of preference for extracranial carotid disease screening, full identification and delineation can difficult in patients with short thick necks, high bifurcations or a distally positioned ECCAs. This modality is also operator dependent. We routinely utilize CTA of the cervical and head vasculature in patients with neurological impairment 


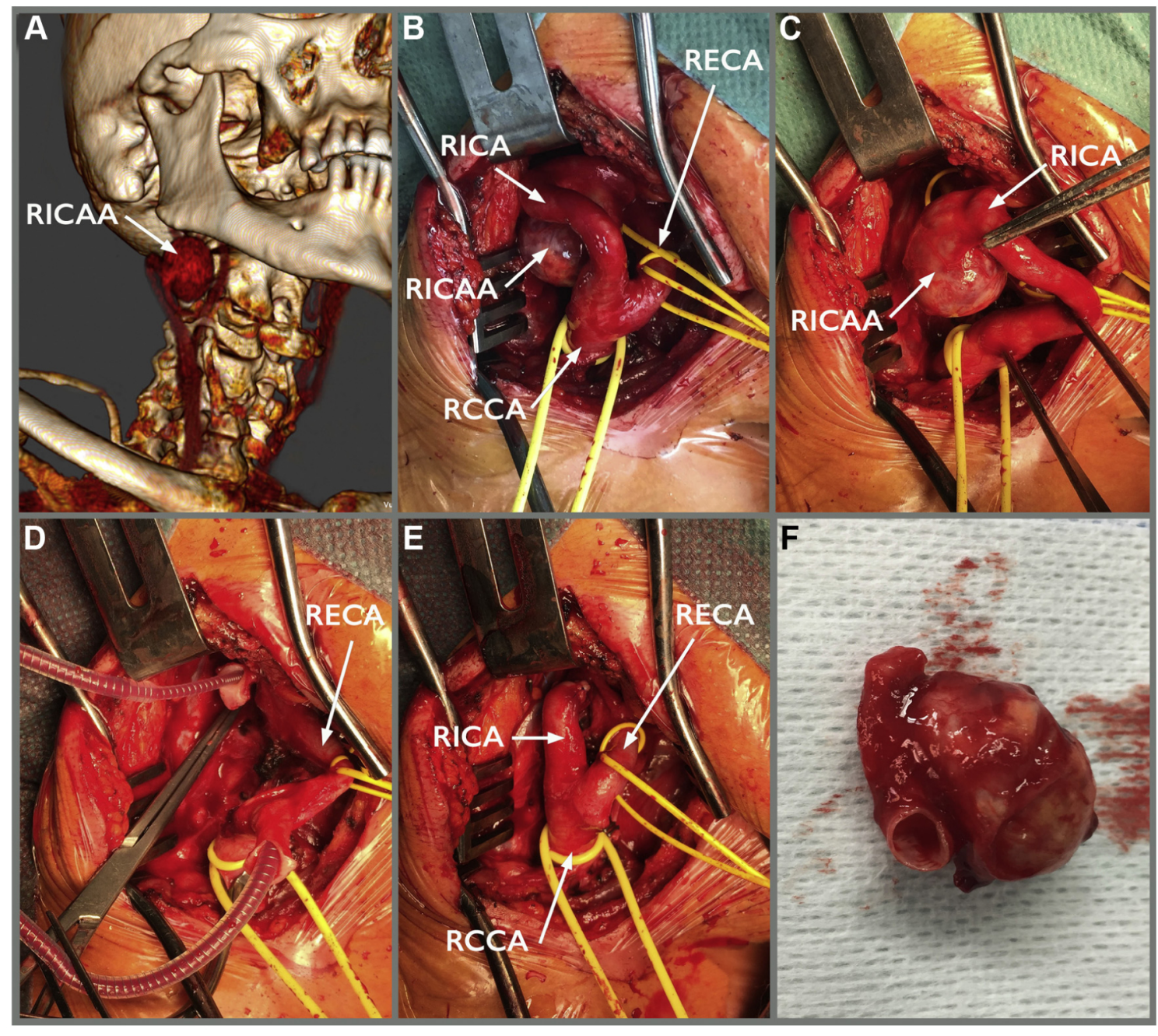

Fig. 2. (A) Computed tomography angiography 3D reconstruction with saccular right internal carotid artery aneurysm (RICAA). (B) Intraoperative image of the standard presternocleidomastoid incision allowing the access to the right common carotid artery (RCCA), right internal carotid artery (RICA), and right external carotid artery (RECA). Note the tortuous tract of the RICA at the upper segment related to the saccular RICAA. (C) RICAA is retracted down to have full exposition. (D) Sundt shunt inserted between the common and internal carotid arteries after aneurysm resection. (E) Direct end-to-end repair with 5-0 prolene. (F) Complete excision of the RICAA and of the involved segment of RICA. even if ultrasound is normal. CTA allows the correct spatial representation of the ECAA, is especially useful for detecting high lesions, and is useful for evaluation of synchronous disease when visualizing the supraaortic trunks. CTA may also visualization tears in the arterial wall indicating a traumatic or dysplastic dissection as the etiology of the ECAA.

We are absolutely convinced, and not only on the basis of our limited experience, but in accordance with the results of the literature ${ }^{9-11}$ of the usefulness operative intervention for ECAAs even in asymptomatic patients and regardless of aneurysm size. This reinforced by the poor results of conservative therapy, with its high risk of cerebral thromboembolic complications. ${ }^{12-14}$ There is also a theoretical risk of rupture, although this is rare and has only been described sporadically. ${ }^{15}$

Until the early 1950s, ligation of the carotid artery was the surgical method of choice, with an associated high stroke risk of approximately $30 \% .{ }^{16}$ Presently ligation of the internal carotid artery is primarily reserved for extreme emergency situations, such as massive, uncontrolled hemorrhage due to rupture. At present, open surgical exploration with aneurysm resection with or without direct repair or an interposition graft remains the gold standard. ${ }^{17,18}$ Attigah et al, ${ }^{7}$ from their retrospective series of 57 patients, establish a morphological 
TYPE I

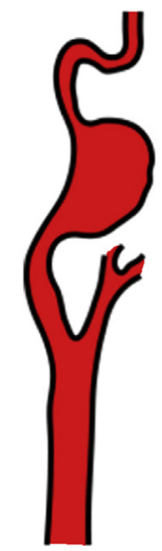

Aneurysm of internal carotid artery distal to bifurcation
TYPE II

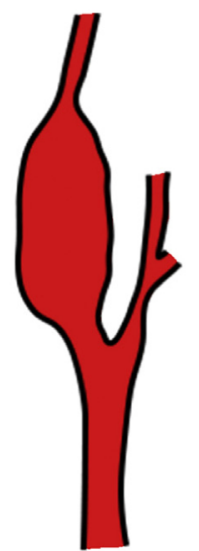

Aneurysm of internal carotid artery
TYPE III

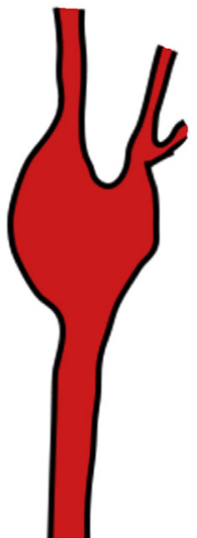

Aneurysm of carotid bifurcation
TYPE IV

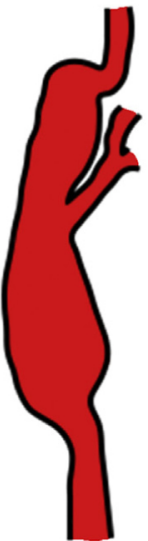

Aneurysm of common and internal carotid artery
TYPE V

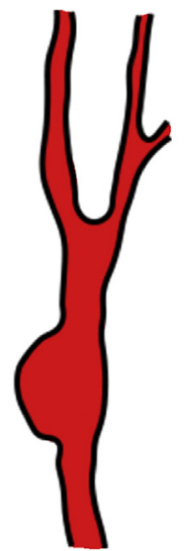

Aneurysm of common carotid artery
Fig. 3. Morphological classification of extracranial carotid artery aneurysm as proposed by Attigah et al and different surgical therapeutic modalities in accordance with each lesion type. Type I can almost always be reconstructed by resection and end-to-end anastomosis. Type II can be reconstructed with vein or Dacron graft interposition. Type III can be locally resected and then reconstructed by aneurysmorrhaphy, patch angioplasty or a Dacron graft interposition. Type IV can be reconstructed with vein grafts. Type V can be reconstructed with Dacron grafts. classification of carotid aneurysm and different surgical therapeutic modalities in accordance with each lesion type (Fig. 3). Results of open surgical treatment combining these different surgical strategies is reported in the literature with mortalities that range from $0 \%$ to $7 \%$, perioperative stroke from $0.7 \%$ to $11 \%$, cranial nerve injury from $0 \%$ to $66 \%$, hematoma from $0 \%$ to $5 \%$, acute renal failure from $0 \%$ to $1.5 \%$, thrombosis from $0 \%$ to $6 \%$, myocardial infarction from $0 \%$ to $1.7 \%$, and infection from $0 \%$ to $1.7 \% .^{5-8}$ Our case was a type I ECAA and was treated with aneurysmectomy and end-to-end anastomosis. We use a shunt as an adjunctive tool to maintain cerebral flow during the open surgical repair because we feared a higher rate of stroke after clamping as compared with occlusive pathology. We theorized that intracerebral collateralization would be less well developed in aneurysmal pathology, although there is no literature evidence of this. Practically we noted that a straight shunt was helpful in maintaining alignment of the redundant ICA, especially in type I ECAAs as in our patient. In cases where interposition grafting is necessary, the small caliber of the shunt would allow its insertion through a vein or prosthetic graft. ECCA repair is a much more demanding procedure than carotid endarterectomy and we recommend the use of shunt in the absence of adequate cerebral collateral blood flow and/or contralateral carotid occlusion, especially in patients who have had a previous stroke.

Alternative treatments for ECCAs have been reported with endovascular techniques in some recent publications; however, the data on this are relatively scarce without much long-term follow-up and need further investigation. Endovascular techniques used to treat ECCA included bare-metal stents with or without trans-stent coiling and more recently the use of covered stents.

In our opinion, the choice between open and endovascular treatment depends on the etiology, localization, symptoms, and characteristics of the lesion. True aneurysms often have significant thrombus burden and for this reason we preferred to treat them with open surgical repair, with a meticulous dissection and with minimal manipulation of the aneurysm to reduce risk of embolization. Moreover, we reserved the endovascular approach for pseudoaneurysms, and we limited it to noninfected cases. We think that endovascular repair is a good treatment when localization of the aneurysm is very high in the ICA or very low in the CCA, and also open surgery represents a challenge because of a hostile neck. It is important to 
remember that endovascular treatment cannot relieve compression-related symptoms because the existing aneurysmal sac will still cause a mass effect.

Most of the data in both open and endovascular intervention are retrospective case series or case reports. The lack of evidence-based treatment algorithm means that clinicians will have to determine individualized management strategies for this uncommon, but serious clinical condition in the light of potential complications. Presently, resection of the aneurysm with restoration of blood flow is still considered the gold standard with acceptable procedural risk and a low risk of late stroke.

\section{REFERENCES}

1. Radak D, Davidović L, Vukobratov V, et al. Carotid artery aneurysms: Serbian Multicentric Study. Ann Vasc Surg 2007;21:23-9.

2. Johnston KW, Rutherford RB, Tilson MD, et al. Suggested standards for reporting on arterial aneurysms. J Vasc Surg 1991;13:452-8.

3. Fankhauser GT, Stone WM, Fowl RJ, et al. Surgical and medical management of extracranial carotid artery aneurysms. J Vasc Surg 2015;61:389-93.

4. Monson DO, Saletta JD, Freeark RJ. Carotid vertebral trauma. J Trauma 1969;9:987-99.

5. El-Sabrout R, Cooley DA. Extracranial carotid artery aneurysms: Texas Heart Institute experience. J Vasc Surg 2000:31:702-12.

6. Zhou W, Lin PH, Bush RL, et al. Carotid artery aneurysm: evolution of management over two decades. J Vasc Surg $2006: 43: 493-6$
7. Attigah N, Külkens S, Zausig N, et al. Surgical therapy of extracranial carotid artery aneurysms: long-term results over a 24-year period. Eur J Vasc Endovasc Surg 2009;37: $127-33$.

8. Pulli R, Dorigo W, Alessi Innocenti A, et al. A 20-year experience with surgical management of true and false internal carotid artery aneurysms. Eur J Vasc Endovasc Surg 2013;45:1-6.

9. Neelakandhan K, Matta R. Extracranial carotid artery Aneurysms.pdf. Int Angiol 1996;15:316-20.

10. Redaelli C, Carrel T, Turina M. Surgery of extracranial aneurysms of the carotid artery. Analysis of 8 cases. Chirurg:620-4, http://www.ncbi.nlm.nih.gov/pubmed/ 1935398, 1991;62.

11. Rossi P, Mirallie E, Pittaluga P, et al. Bilateral extracranial aneurysms of the internal carotid artery. A case report. J Cardiovasc Surg (Torino) 1997;38:27-31.

12. Liapis CD, Gugulakis A, Misiakos E, et al. Surgical treatment of extracranial carotid aneurysms. Int Angiol 1994;13: $290-5$.

13. Zwolak R, Whitehouse W, Knake J, et al. Atherosclerotic extracranial carotid artery aneurysm. J Vasc Surg 1984;1: $415-22$.

14. Davidovic L, Kostic D, Maksimóvic Z, et al. Carotid artery aneurysms. Vascular 2004;12:166-70.

15. Siablis D, Karnabatidis D, Katsanos K, et al. Extracranial internal carotid artery aneurysms: report of a ruptured case and review of the literature. Cardiovasc Intervent Radiol 2004;27:397-401.

16. Welling R, Taha A, Goel T, et al. Extracranial carotid artery aneurysms. Surgery 1983;93:319-23.

17. Welleweerd JC, Den Ruijter HM, Nelissen BGL, et al. Management of extracranial carotid artery aneurysm. Eur J Vasc Endovasc Surg 2015;50:141-7.

18. Welleweerd JC, Moll FL, De Borst GJ. Technical options for the treatment of extracranial carotid aneurysms. Expert Rev Cardiovasc Ther 2012;10:925-31. 